\title{
The Influence of the System of Physical Education of Higher Educational School on the Level of Psychophysiological Qualities of Young People
}

\author{
Volodymyr Klymovych ${ }^{1}$, Mukola Korchagin ${ }^{2}$, Oleh Olkhovyi ${ }^{3}$, Serhii Romanchuk ${ }^{1}$ and Artur Oderov ${ }^{1}$ \\ ${ }^{1}$ National Academy of the Army, Department of Physical Education, Special Physical Training and Sports, Lviv, Ukraine, ${ }^{2}$ Kozhedub Air Force \\ University, Department of Physical Education, Special Physical Training and Sports, Kharkiv, Ukraine, ${ }^{3}$ Black Sea Petro Mohyla National University, \\ Department of Olympic and Professional Sports, Mykolaiv, Ukraine
}

\section{Abstract}

In terms of functioning of physical education system in higher educational establishments, a four-year educational pedagogical experiment with the application of the directional technology of acquiring professional-applied motor skills was implemented. According to the results of approbation of experimental technology, a reliable improvement in the state of psychophysiological qualities was recorded in the study group: evaluation of the process of main nervous processes excitation - by 125.32 Ms ( $p<0.001)$, the forces of the excitation process, internal inhibition and mobility of the main nervous processes - by $145.99 \mathrm{Ms}(\mathrm{p}<0.001)$, "an adequate indicator of the relative change in the strength of the excitation process, internal inhibition and mobility of the main nervous processes" - by 20.66 Ms ( $p<0.001)$.
\end{abstract}

Key words: young, latent period, psychophysiological state

\section{Introduction}

Physical education has always been one of the essential components of the process of preparing young people for promising employment and adapting them to the social environment. The current system of physical education of a higher educational school now creates certain preconditions for ensuring the success of further professional activities and indirectly manifests itself therein, mainly through factors such as: will, state of health, physical and other personal qualities of the individual. However, a functioning system does not effectively provide the initial psychophysiological readiness of student youth for professional activity. This is confirmed by the following results of the research.

In the course of studying in higher educational institutions in the body of students young people psychophysiological processes take place. This has been accompanied by psychological and physical activity and are determined by a number of elements and factors of the educational process, each of which has a tendency to achieve the useful final studying result. That is why the question of the dynamics of assessing the psychophysiological qualities of the youth organism is in the plane of our interests (Ivanova, 1992; Lyzogub, 1999; Ostapenko, 2014).

The focused professional-applied discipline of the discipline "Physical education and sports" promotes the adaptation of the functional capabilities of the youth organism to further professional activity (Klymovych, Olkhovyi, \& Romanchuk, 2016; Klymovych \& Olkhovyi, 2016). However, due to the influence of a number of factors of the external and internal environments, professional-oriented direction contributes to the positive dynamics of the process of adaptation to further work, and on the other hand - requires additional efforts from the future specialists and a sufficient level of physical fitness for exercise (Korolchuk, 2002; Korchagin, Kurbakova, \& Olkhovyi, 2017; Ostapenko, 2014).

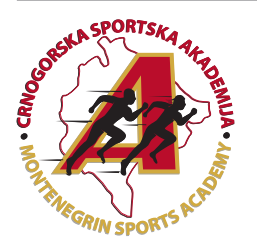

Correspondence:

V.B. Klymovych

National Academy of the Army, Department of Physical Education, Special Physical Training and Sports, Lviv, Ukraine

E-mail: klimovichvolodymyr@gmail.com 
The analysis of recent researches and publications has revealed that the greatest activation (in percentage of) psychophysiological processes of young organism to the new conditions of the educational environment and directly student life begins with the first courses of study, due to the influence on the organism of long and short-term various situations (Klymovych et al., 2016). The consequences of the influence of certain stages of the educational process in higher educational institutions on the body of young people in term of functioning of the current system of present physical education have been studied in detail (Ostapenko, 2014). However, the dynamics of indicators that characterizes the level of psycho-physiological processes occurring in the body of those studying in higher education institutions before the transfer of the educational system and the conditions of promising professional activity by means of physical training during the entire study period is not fully characterized.

The purpose is to experimentally examine the influence of the system of physical education of a higher educational school on the level of psychophysiological qualities of youth.

\section{Methods}

To determine how the impact of the directed technology on the acquisition of professional-applied motor skills by graduates of higher educational institutions of on the state of psychophysiological qualities of boys has influenced, we conducted a pedagogical experiment carried out under the conditions of the normal functioning of the educational process of higher educational institutions and had the character of the formative experimental work. The research was conducted throughout the period of training and fully coincided with the hours of the curriculum of youth training, which did not cause the need for organizational restructuring of the educational process. However, in the pilot sample, these classes were conducted in accordance with the content of the experimental curriculum developed with the use of experimental methodological influence in the form of directed technology for the acquisition of professional-applied motor skills.

To obtain a rational advantage over the continuous diagnosis of the general population for a large number of parameters and more accurate information about the investigated contingent in a broader program, we applied a sample survey of individuals of the general population based on its staffing. The volume of the research sample (n) was limited to $20 \%$ of the total population. So, from the general population of those who entered higher education, two similar educational groups $(n=47)$ were selected, one of which was the control $(n=24)$, and the other - an experimental $(n=23)$ sample population.

Taking into account that the conditions of the educational environment in which higher education is acquired influences the future specialist as a set of synergistic and antagonistic actions, and the organism responds to these actions as a whole, determining the level of professional ability of the cadets in the studied groups was carried out in a complex manner, with the obligatory inclusion evaluation of brain functions and servicing systems and organs (Korchagin et al., 2017; Lyzogub, 1999).

The professional activity of modern youth is accompanied by such an element as the adoption of managerial decisions on one or another situational manifestation or circumstances during the performance of functions for professional appointment (Makarenko, 1984). This professional component, as a form of higher nervous activity manifestations, is realized as a result of interaction in the cerebral cortex of two nervous processes - excitation and inhibition. The dynamics of these specific properties of the main nervous processes determined by force, motion and balance (psychophysiological qualities of student youth) was investigated using the applied methods of assessing the state of the nervous system - by the amount of time of the latent period of a simple sensorimotor reaction (LPSSMR), a complex sensorimotor reaction with a choice LPCSMRwC) and the time of decision-making (the difference between a complex and simple sensory-motor reaction) (Korolchuk, 2002; Olkhovyi, 2015).

The evaluation of the qualities of the main nervous processes using sensorimotor reactions was carried out as follows. The strength of the excitation process was estimated by the amount of time LPSSMR: its reduction indicates an increase in the strength of the excitation process. The estimation of internal inhibition was carried out taking into account the relative frequency of mistakes on the braking signal, the increase of this index indicates the weakening of the internal inhibition force. In order to evaluate the motility of the nervous processes, the indicators of LPCSMR were compared.

A simple sensorimotor reaction is one of the informative methods for characterizing the strength of the nervous processes. To record the speed of a simple sensorimotor reaction, a computer program "Latent Reaction" (Klymovych \& Olkhovyi, 2016) was used. The explorer is given a light signal, which he must respond to by pressing the left mouse button with the maximum speed. The signal was activated automatically, at intervals of up to 3-4 seconds. LPSSMR recorded the program automatically, the result of each subject was recorded as a separate file, fixed the number of errors. After 2 training attempts, the results of a series of 10 signals are recorded and the average arithmetic index of LPSSMR is calculated.

The complex sensor-motor reaction with the choice of light stimuli allowed to investigate the strength of the processes of excitation and internal inhibition, as well as the motor of the main nervous processes. The research program uses the same program as for LPSSMR research, but different light signals (flashes of red and green light bulbs) are fed in a certain sequence. The switching off of red and green signals is carried out by the right and left mouse buttons. The next flash occurs after 2-3 seconds after the corresponding reaction. When determined by LPCSMRwC, the red light bulb being surveyed reacts by pressing the left button, and on the flash of green - the right one.

If the the researched object does the opposite, the bulb will not go out, and this will indicate an error. The computer automatically registers the response time to an accuracy of $0.001 \mathrm{~s}$ and the number of errors. In the process of research LPCSMRwC surveyed is provided 25 light signals, of which 15 red and 10 green. Increasing LPCSMRwC or increasing the relative error rate after processing the signal value of the stimulus indicates a decrease in the mobility of nervous processes.

By establishing the difference between LPSSMR and LPCSMRwC an adequate indicator of the relative change in strength and excitement and internal inhibition of the nerve process was determined (Korolchuk, 2002; Olkhovyi, 2015). This by-side indicator has become an integral part of the research of the ability and promptness of graduates' decision-making, which will facilitate their professional activity in the future in relation to one or another situational manifestation or circum- 
stances during the performance of functions for professional appointment.

\section{Results}

The homogeneity of the studied samples was confirmed by the absence of significant differences in the average indices of the assessment of psycho-physiological qualities based on the results of the comparative analysis of the results of the entrance control in the representatives of the control and experimental population groups that were involved in the implementation of the formative pedagogical experiment (Table 1), namely:

Level of excitability of the central nervous system (LPSSMR) - at $2.98 \mathrm{Ms}$ at $\mathrm{p}>0.05$;

The strength of the process of excitation, internal inhibition and mobility of the main non-core processes (LPCSMRwC) - at 0.14 Ms at $\mathrm{p}>0.05$;

The difference between LPSSMR and LPCSMRwC (Time of decision-making) - at $3.12 \mathrm{Ms}$ at $\mathrm{p}>0.05$.

Table 1. Dynamics of assessment of psychophysiological qualities of young people CG $(n=24)$ and EG $(n=23)$ during the experiment

\begin{tabular}{|c|c|c|c|c|c|c|c|c|c|}
\hline \multirow[b]{2}{*}{$\begin{array}{l}\text { Indexes } \\
\text { (unit measurement) }\end{array}$} & \multirow[b]{2}{*}{ Group } & \multirow[b]{2}{*}{$\begin{array}{l}\text { Period } \\
\text { researches }\end{array}$} & \multirow[b]{2}{*}{$\overline{\mathbf{X}}$} & \multirow[b]{2}{*}{ m } & \multirow[b]{2}{*}{$\mathbf{S}$} & \multirow[b]{2}{*}{$\begin{array}{c}\text { Changes } \\
\%\end{array}$} & \multirow[b]{2}{*}{$\begin{array}{c}B E-A E \\
t\end{array}$} & \multicolumn{2}{|c|}{ CG - EG } \\
\hline & & & & & & & & $\begin{array}{c}\text { BE } \\
\mathbf{t}\end{array}$ & $\underset{t}{\mathrm{AE}}$ \\
\hline \multirow{4}{*}{ LPSSMR (Ms) } & \multirow{2}{*}{ CG } & $\mathrm{BE} *$ & 440.95 & 16.01 & 78.44 & \multirow{2}{*}{4.8} & \multirow{2}{*}{1.49} & \multirow{4}{*}{0.11} & \multirow{4}{*}{4.4} \\
\hline & & $A E^{*}$ & 419.8 & 21.37 & 104.7 & & & & \\
\hline & \multirow{2}{*}{ EG } & BE & 443.93 & 21.83 & 104.7 & \multirow{2}{*}{28.23} & \multirow{2}{*}{4.99} & & \\
\hline & & $\mathrm{AE}$ & 318.61 & 8.47 & 40.64 & & & & \\
\hline \multirow{4}{*}{ LPCSMRwC (Ms) } & \multirow{2}{*}{ CG } & $\mathrm{BE}$ & 491.11 & 16.9 & 82.8 & \multirow{2}{*}{6.49} & \multirow{2}{*}{2.19} & \multirow{4}{*}{0.01} & \multirow{4}{*}{4.67} \\
\hline & & $\mathrm{AE}$ & 459.27 & 22.54 & 110.4 & & & & \\
\hline & \multirow{2}{*}{ EG } & BE & 490.97 & 20.17 & 96.71 & \multirow{2}{*}{29.74} & \multirow{2}{*}{6.4} & & \\
\hline & & $\mathrm{AE}$ & 344.98 & 9.47 & 45.42 & & & & \\
\hline \multirow{4}{*}{ Time for decision (Ms) } & \multirow{2}{*}{ CG } & $\mathrm{BE}$ & 50.15 & 2.45 & 12.0 & \multirow{2}{*}{21.3} & \multirow{2}{*}{1.49} & \multirow{4}{*}{0.9} & \multirow{4}{*}{5.62} \\
\hline & & $\mathrm{AE}$ & 39.47 & 1.87 & 9.16 & & & & \\
\hline & \multirow{2}{*}{$\mathrm{EG}$} & $\mathrm{BE}$ & 47.03 & 2.45 & 11.78 & \multirow{2}{*}{43.03} & \multirow{2}{*}{7.35} & & \\
\hline & & $\mathrm{AE}$ & 26.37 & 1.38 & 6.65 & & & & \\
\hline
\end{tabular}

Legend: $\mathrm{BE}$ - before the experiment, $\mathrm{AE}$ - after the experiment

\section{Discussion}

Based on the results of our research, we recorded an improvement (Table 1.) of the level of qualities of the main nervous processes in the boys of the control group ( $n-24)$ who were trained in generally acceptable physical education programs, namely:

Level of excitability of the central nervous system (LPSSMR) - at 20.39 Ms, at $\mathrm{p}>0.05$;

The strength of the process of excitation, internal inhibition and mobility of the main non-core processes (LPCSMRwC) - at $31.84 \mathrm{Ms}$, with $\mathrm{p}<0.05$;

The difference between LPSSMR and LPCSMRwC (Time of decision-making) - at $3.12 \mathrm{Ms}$ at $\mathrm{p}>0.05$.

A comparative analysis of the initial level of evaluation of the process of excitation of the main nervous processes in the representatives of the studied samples recorded its significant advantage (Table 1.) for those who studied under the experimental technology:

Level of excitability of the central nervous system (LPSSMR) - at 101.19 Ms, at $\mathrm{p}>0.001$ (Figure 1.)

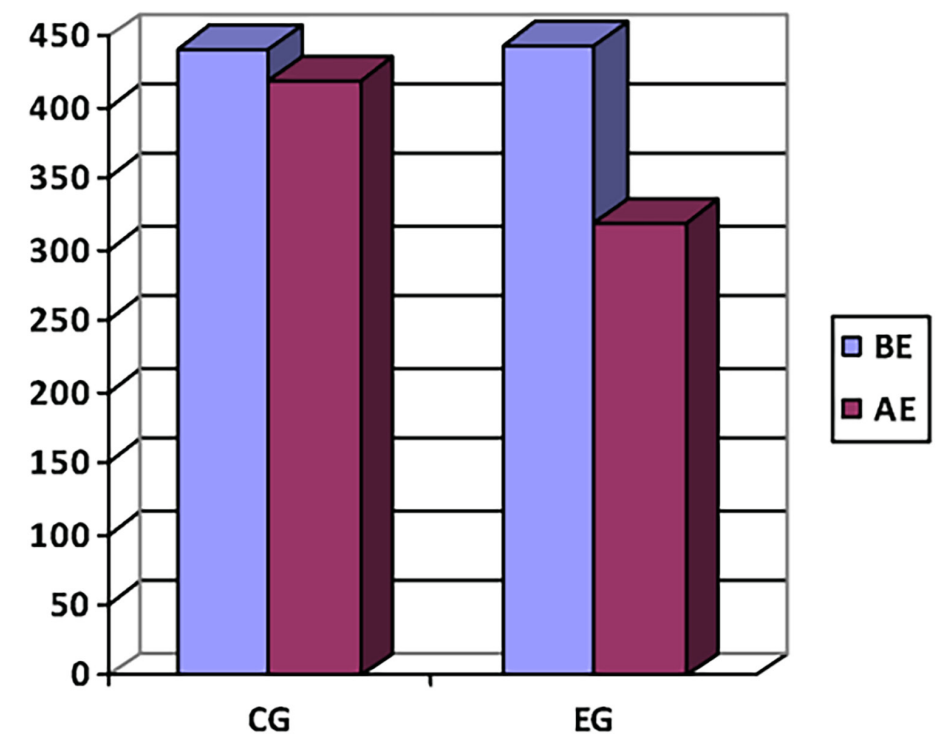

Figure 1. Level of excitability of the central nervous system (LPSSMR) 
The strength of the process of excitation, internal inhibiti- $\quad$ - at $114.29 \mathrm{Ms}$, with $\mathrm{p}<0.001$ (Figure 2.). on and mobility of the main non-core processes (LPCSMRwC)

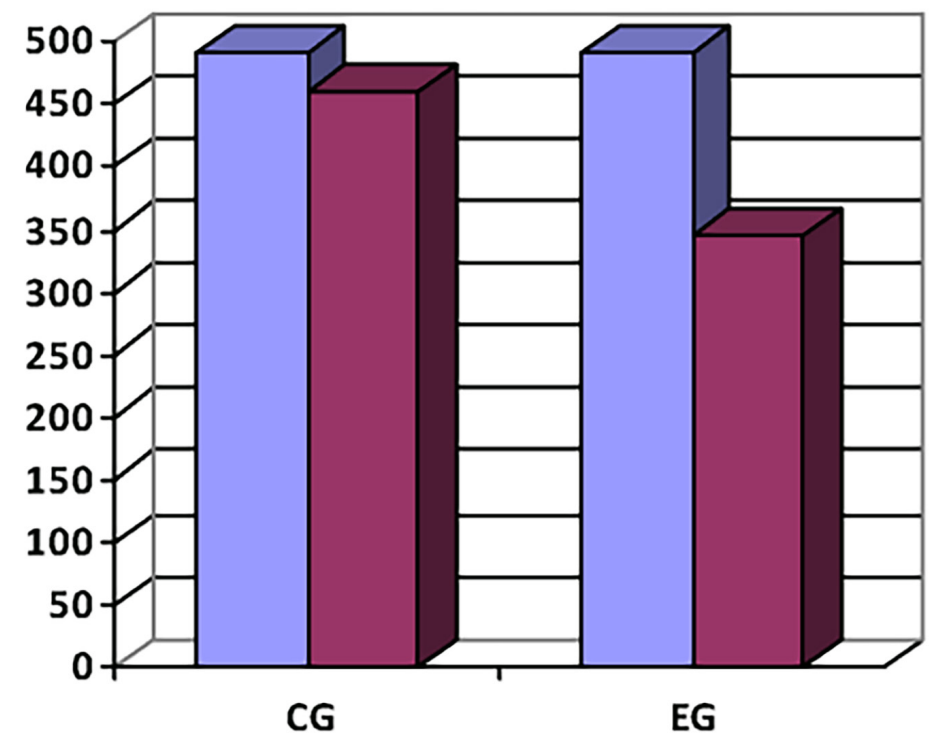

\section{$\square \mathrm{BE}$ \\ $\square \mathrm{AE}$}

Figure 2. LPCSMRwC (Ms)

The difference between LPSSMR and LPCSMRwC (Time of decision-making) - at 13.1 Ms at p>0.05. (Figure 3.).

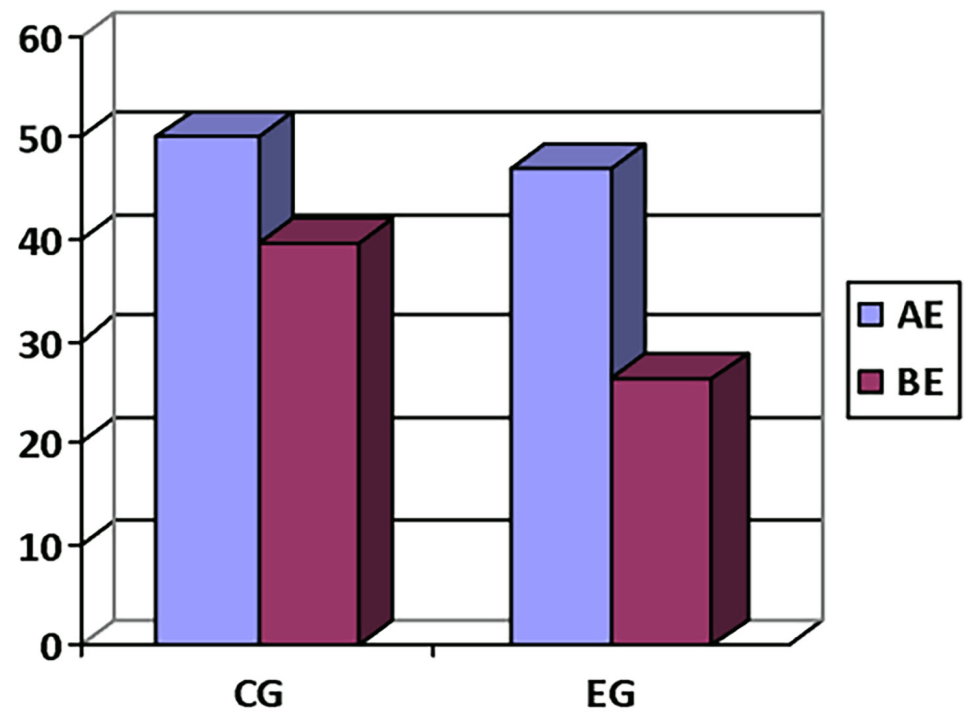

Figure 3. Time for decision (Ms)

The main result of the research carried out was the fact that we have established the presence of indirect reliable positive effect of the experimental technology of acquiring professional-applied motor skills on the stability of psychophysiological qualities (Table 1.) of the surveyed. Thus, at the end of the experiment, the estimation level of the process of excitation of the main nervous processes with the help of LPSSMR at the representatives of the EG (n-23) indicates an improvement of this indicator by $125.32 \mathrm{Ms}$, at $\mathrm{p}<0.001$. The strength of the excitation, internal inhibition and mobility of the main nervous processes in the EG (Table 1.) also experienced significant positive changes at $145.99 \mathrm{Mts}$, with $\mathrm{p}<0.001$. In this case, "an adequate indicator of the relative change in the strength of the process of excitation, internal inhibition and mobility of the main nervous processes (Klymovych, 2016). Time of decision-making (Table 1.) - significantly different from the input data for boys EG at $20.66 \mathrm{Ms}$, at $\mathrm{p}<0.001$.

Above statistical analysis revealed a reliable advantage of indicators level of the stability of the psycho-physiological qualities of the representatives of the experimental sample to the influence of factors of the educational process. What formed a more favorable reaction of their organism to the professional factors of further professional activity and the acquisition of professional-applied motor skills.

The obtained statistics confirmed our assumption that the experimental application of the technology of graduates' acquiring of professional-applied motor skills indirectly has a positive effect on the reliable dynamics of psychophysiological qualities of boys (17-22 years) based on the results of studies at a higher educational school.

In the long run, we continue to investigate the effectiveness of the functioning of the system of physical education in the 
higher education school based on the results of the application of the directed technology for the acquisition of vocational and applied motor skills by boys.

\section{Acknowledgements}

There are no acknowledgements.

\section{Conflict of Interest}

The authors declare that there are no conflicts of interest.

Received: 28 March 2019 | Accepted: 06 May 2019 | Published: 01 June 2019

\section{References}

Ivanova, E.M. (1992). Psychotechnology of studying a person in labour activity.

A methodical manual. Publishing House of Moscow State University, 83-86.

Klymovych, V., Olkhovyi, O., \& Romanchuk, S. (2016). Adoption of youth`s bodies to educational conditions in higher educational institutions.
Journal of Physical Education and Sport, 3(1), 620-622.

Klymovych, V. \& Olkhovyi, O. (2016). Influence on the dynamics of psychophys iological qualities. Actual scientific research in the modern world: Collection of scientific works XIV International (49-53).

Korolchuk, M.S. (2002). Psychophysiology of activity. KIMU, Kyiv. (in Ukr.)

Korchagin, M., Kurbakova, S., \& Olkhovyi, O. (2017). Dependence of the success of professional activity of servicemen-operators on the level of psychophysiological qualities. Sports Gazette of Prydniprovia, 5(3), 65-68. Lyzogub, V.C. (1999). Formation of the strength of the nervous processes in human ontogenesis. Bulletin of the Taras Shevchenko Kyiv University, 7(5), 65-68.

Makarenko, N.V. (1984). Latent period of sensory-motor reactions in persons with different functional mobility of the nervous system. Journal. higher nervous, 34(6), 1041-1047.

Ostapenko, Y.A. (2014). Professional-meaning psychophysiological qualitie of the information-logical group of specialties. Pedagogics, psychology and medical-biological problems of physical education and sport. ed. S.S. Yermakova, 4(6), 34-39.

Olkhovyi, O.M. (2015). Theory and methodology of scientific research in physical education and sport. KSAPC, 1(2), 143. 